\title{
Myeloproliferative Disorders and Its Associated Mutations
}

\author{
Kaveh Tari ${ }^{1}$, Reza Yarahmadi ${ }^{2}$, Amir Tabatabaei ${ }^{2}$, Fakhredin Saba ${ }^{1}$, Saeid Abroun ${ }^{1 *}$, Amir Atashi ${ }^{1}$, Masoud Soleimani ${ }^{1}$ \\ ${ }^{1}$ Department of Hematology, Faculty of Medical Sciences, Tarbiat Modares University, Tehran, Iran. \\ ${ }^{2}$ Department of Laboratory Sciences, School of Paramedical Sciences, Ahvaz Jundishapur University of Medical sciences, Ahvaz, Iran.
}

Received: 2 Aug 2014

Revised : 5 Sep 2014

Accepted: 20 Sep 2014

Corresponding Authors:

Saeid Abroun

Department of Hematology, Faculty of

Medical Sciences, Tarbiat Modarres

University, Tehran, Iran

E-mail: Abroun@modares.ac.ir

\begin{abstract}
Myeloproliferative Neoplasm (MPN) is a clonal disorder of hematopoietic stem cells (HSC). MPN is categorized as 8 subclasses, including chronic myeloid leukemia (CML), polycythemia vera (PV), essential thrombocytopenia (ET), primary myelofibrosis (PMF), systematic mastositosis (SM), chronic eosinophilic leukemia (CEL), chronic neutrophilic leukemia (CNL), and unclassified myelofibrosis disorders (UMPN). It usually occurs in 5th to 7th decade of life. However, CNL and ET have been also observed in children. A lot of mutations have been identified in these disorders which Jak2V617F is the most important mutation. Moreover, other than JAK2V617F, several somatic mutations have been reported in MPN patients. Such mutations include MPL, TET2, ASXL1, IDH1, IDH2, CBL, LNK, IKZF, and EZH2 in precursor stem cells. The role of mutations mentioned is not clear in pathogenesis of this disease. Therefore, in this study, mutations in different stages of myeloproliferative disorders have been reviewed.
\end{abstract}

Keywords: MPN; Hematopoietic stem cells; Mutation

Please cite this article as: Tari K, Yarahmadi R, Tabatabaei A, Saba F, Abroun S, Atashi A, Soleimani M. Myeloproliferative Disorders and Its Associated Mutations. Res Mol Med. 2014; 2 (4): 3-11

\section{Introduction}

Classic myeloproliferative syndrome with negative Philadelphia chromosome includes polycythemia Vera $(\mathrm{PV})$, essential thrombocythemia (ET) and primary meylofibrosis (PMF) It seems MPNs with negative Philadelphia chromosome are a chronic myeloid neoplasm resulting from amalignant mutation. Clinical symptoms of these patients include erythrocytosis, thrombocytosis, leukocytosis, pancytopenia, extra medullary hematopoiesis, increased risk of thrombosis and transforming acute myeloid leukemia. Patient's longevity of MPN with negative Philadelphia chromosome is different such as 5-7 year survival in PMF and more than 15-year survival in PV and ET $(1,2)$.

In 2008, WHO reclassified myeloid and lymphoid and improved the 2001 classification. At present, classification of myeloid leukemia includes 5 groups, including AML, MDS, MPN, MDS/MPN and myeloid and lymphoid leukemia with eosinophilia and recombination in PDGFR or FGFR1.Totally, MPN can be classified into 8 subclasses such as chronic myeloid leukemia (CML), polycythemia vera (PV), essential thrombocytopenia(ET),primary myelofibrosis
(PMF), systematic mastocytosis (SM), eosinophilic leukemia (CEL), chronic neutrophilicleukemia (CNL), and unclassified myeloproliferative (UMP). MPN is a clonal disorder in hematopoietic stem cells (HSC), occurring in fifth and seventh decade of life, however, CML and ET have also been observed in children. The annual incidence of MPN is 6110 per 100.000 populations $(3,4)$.

A lot of mutations have been identified in these disorders that JAK2 V617F is believed to be the most important. Recently, despite JAK2V617F, several somatic mutations have been reported in patients with MPN, including MPL, TET2, ASXL1, IDH1, IDH2, CBL, LNK, IKZF, EZH2 in precursor stem cells. However, the pathogenic role of mentioned mutations is still unclear (5-7).

\section{Signaling of JAKs and STATs}

JAKs are relatively large proteins with more than 100 amino acids with molecular weight about 120-140 kilo Dalton that have 7 domains, including JH1 domain, active catalytic domain of tyrosine kinas in carboxy-terminal. $\mathrm{JH} 1$ is adjacent to $\mathrm{JH} 2$, that $\mathrm{JH} 2$ is 
a catalytically inactive pseudokinase domain, a domain in amino-terminal known SH2 (JH3-JH4) and FFEM domain (Band-4, erzin, Radixin, moesin), including (jH6 and $\mathrm{jH} 7$ ). $\mathrm{SH} 2$ domain may have the role of scaffold rather than signaling. Mutation in $\mathrm{SH} 2$ domain of Jak1 has no effect on kinase activity or binding to receptor as well as having a key role in other kinases. Moreover, FRRM domain mediates interaction of membrane proteins and regulatory catalytic activities. Four membrane proteins from JAK family such as TyK2, JAK3, JAK2, and JAK1 have essential role in cytokine pathway in HSCs (8). JAK1, JAK2, JAK3 and Tyk2 genes are located on human chromosomes, including 1P13.3, 9P24, 19P13.1 and 19P13.2, respectively (9) (Figure1).

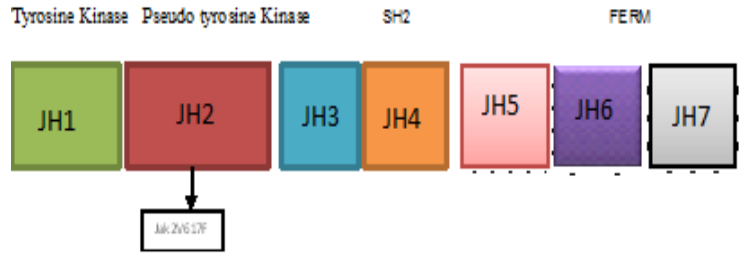

Figure 1. Structure of Janus kinases (JAKs). JAKs have 7 domain including $\mathrm{JH} 1$ domain that is an active catalytic domain of tyrosine kinas in carboxy - terminal, JH2 is a pseudo kinase self-inhibitor domain, a domain in amino-terminal known SH2 (JH3-JH4) and FERM domain (Band - 4, erzin, Radixin, moesin), including (jH6 and $\mathrm{jH} 7$ ).

JAK1 and JAK2 are involved in IFN- $\gamma$ signaling and also accompany with type II cytokine receptors and consist of IL-20, IL-6, IL-10, IL-11, IL-19, and IL22. JAK2 is stimulated through hormone-like cytokines such as growth hormone, prolactin, erythropoietin (EPO), thrombopoietin (TPO), and those have role in proliferation of HSCs, including IL-3 and GM-CSF. JAK1 and JAK3 are accompanied with $\gamma c$ cytokines such as IL-2, IL-4, IL-7, IL-9, IL-15, and IL-21. Finally, tyk2 with JAK1 and JAK2 is associated with type I interferon, P40, IL-12 and IL-23 (10). Hyperactive Janus kinase leads to an abnormal proliferation in a series of hematological malignancies such as myeloid and lymphoid leukemia, Hodgkin lymphoma and B-cell non-Hodgkin lymphomas (11).

In 1985, the firststudyrelatedtointeraction of mutations in JAK kinases and hematological malignancies were performed. Luo et al. (12) indicated that in Hopscth Drosophila gene at position 341, glycine (Gly) is converted to glutamic acid (Glu), which causes leukemia-like disorder in hematopoiesis. Two years later,some studies demonstrated theinteraction between JAK2 chromosomal translocation and human neoplastic growth. Specifically, in children with early precursor-BALL and adults with ACML recognized translocation between JAK2 kinase domain and helixloop-helix were related to ETS from TEL family $(13,14)$.

A high rate of point mutation in JAK2 and MPL, especially in MPN, is a substantial example of patients with aberrant signal transduction pathways. After that, JAK2 became as a promising target for treatment of MPN. Moreover, after the discovery of JAK2 mutations, synthesis of JAK2 inhibitors is increasingly being performed (15).

STATs are transcription factors that were first described by Darnell et al (16). An earlier study signified the role of STATs in transduction of signaling initiated by several cytokines and growth factor. To date, seven genes coding STAT have been identified in mammals, and the post-translational modification/ proteolytic breakage leads to synthesis of additional isoforms of STAT1 and STAT3 (17).

STAT4 and STAT5 have two known forms including STAT $4 \alpha$ and STAT4 $\beta$, STAT5 $\alpha$ and STAT5b, respectively, which are encoded by two separate tandem genes (18).

In an unstimulated cell, STATs are nonphosphorylated proteins in cytoplasm. Following stimulation with cytokine, tyrosine is phosphorylated near cell surface receptors, providing an anchor for STATs through $\mathrm{SH} 2$ domain. When they are connected to the receptors, all members of STAT family are phosphorylated in conserved tyrosine CT terminal followed by response to cytokine stimulation (for example, Y694 in STAT5). Phosphorylation of this site of tyrosine is achieved by growth factor receptors such as JAKs and Src kinase, depending on the cell type and interaction ligand with receptor. Such phosphorylation leads to homo- and heterodimerization of STAT proteins through binding another STAT with SH2 domain in another phosphotyrosine site. When STAT is phosphorylated, dimerized STAT1 is transported to nucleus. Tyrosine phosphorylation in all STATs except STAT2 is regulated through phosphorylation of serine in a conserved domain of PSMP located in a transactivation domain (19-21) (Figure 2).

\section{JAK2 mutation}

JAK2V617F mutation is hidden at valine 617 in the auto-pseudokinase domain of JAK2. Molecular models of pseudokinase domain propose a reaction with activation lobe of kinase domain. Further, structural and functional researches suggest that amino acids located between position 619 and 970, are in maintaining the inhibitory characteristics of pseudokinase domain. Therefore, it has been hypothesized that V617mutation prevents the function of pseudokinase domain as an inhibitor of internals near kinase domain, resulting in aberrant tyrosine kinase activity of JAK2 $(5,22,23)$. 
Furthermore, replacement of V617F leads to activation of JAK2 as well as downstream signals cascades, including transcription STAT pathway, the phosphatidylinositol-inositol 3-kinase signaling pathways (PI3K), and extracellular regulated kinase (ERK). In turn, such mutation induces inappropriate and cytokine-independent proliferation (24-26).

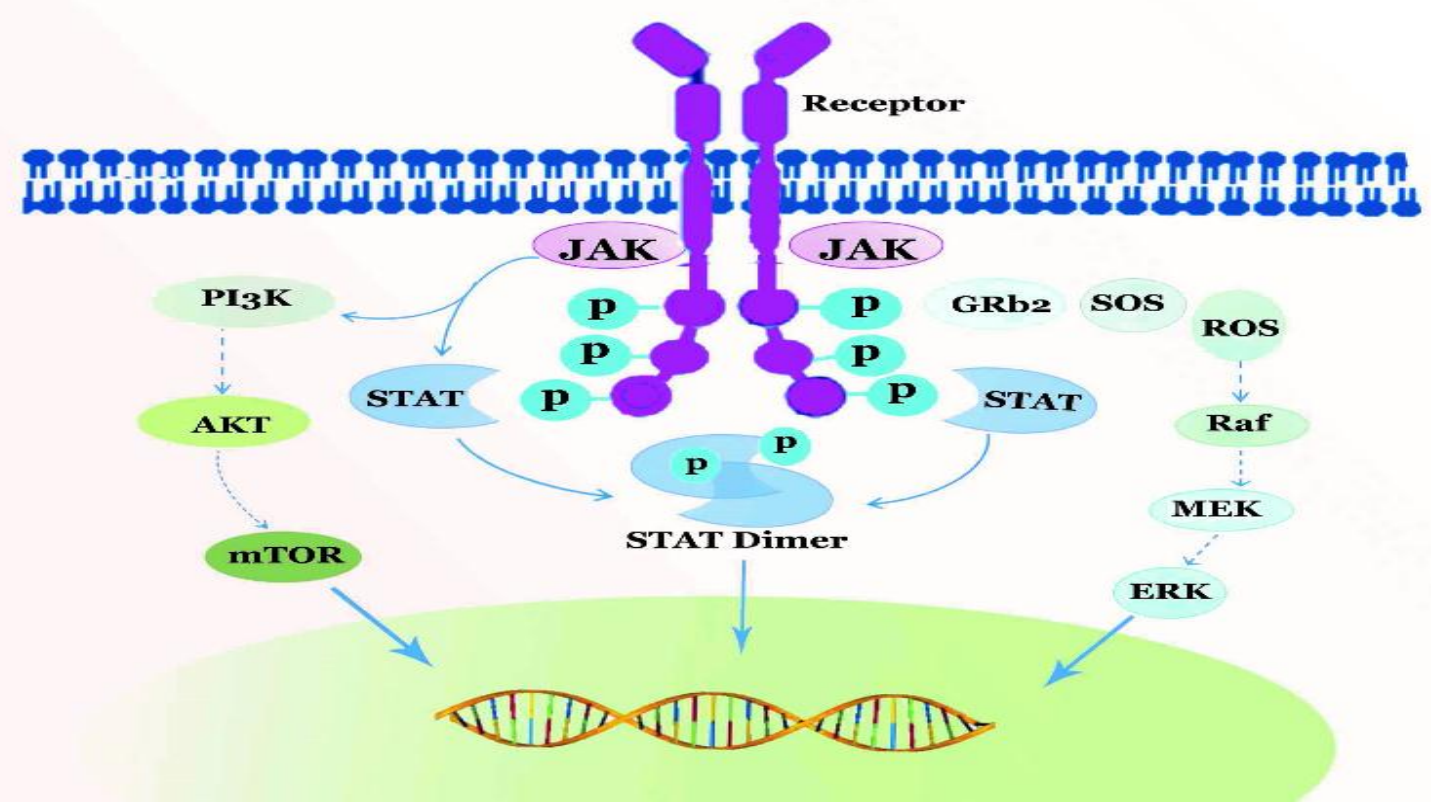

Figure 2. JAK-STAT signaling pathway. STATs (Signal Transducers and Activators of Transcription) are transcription factors that are phosphorylated by JAK (Janus kinases) in response to cytokine activation, then dimerize and move into the nucleus to activate transcription of cytokine-responsive genes.

Researchers have demonstrated that JAK2-T875N led to a permanent activity in in-vitro and induction of MPN with megakaryocyte feature in mice transplanted with bone marrow. Other new mutations in JH2 domain in JAK2 confirmed permanent activation of JAK/STAT pathway, including JAK2K607N mutations and JAK2L611s in patients with AML and ALL, respectively (27-30).

Several fusion proteins related to catalytic activity of the JH1 domain in JAK2 have been reported in leukemia that some of them are mentioned below.

\section{ETV6/TEL-JAK2 Fusion}

The first report on chromosomal translocation related to JAK2 gene was published in 1997 that described translocation $\mathrm{t}(9,12)(\mathrm{P} 24 ; \mathrm{P} 13)$ in a case of PreBALL. This translocation resulted from incorporation of the second oligonucleotide helix-loop-helix of variant of ETS family (E26 transformation-specific or E-twenty-six) with tyrosine kinase JAK2 (31). This initial report was followed by a second study, describing known fusion of TEL-JAK2 resulting from a $\mathrm{t}(9,12)(\mathrm{p} 24 ; \mathrm{p} 13)$ chromosomal translocation in several human leukemia (31). TEL is a member of ETS family of transcriptionfactors. TEL-JAK2 fusionprotein has a permanent activity of kinase, and its overexpression in a murine myeloid cell is caused by interleukin-3 (IL-3)-independent growth (32). These findings were broadly confirmed by independent induction of growth factors, hematopoietic cell transformation and developing myeloproliferative disease (MPD) in mice overexpressed with TEK-JAK2 gene. Subsequently, TEL-JAK2 fusion has been indicated to activate PI3kinase and ERK 1/2 signaling pathway. TEL-JAK2 has been identified in ACML and pre-B and pre-T ALL (33-35).

\section{PCM1-JAK2 fusion}

Finding Jak2V617F activating mutation led to increased interest in sequencing and genetic analysis of JAK2 locus in patients with hematological symptoms and opened a way for identification of several novel translocations in JAK2 gene. In a clinical study in Germany, human auto-antigen gene of pericentriolar material (PCM1) in fusion with JAK2 in men with acute and chronic leukemia was seen with distinct clinical outcomes. Although, this rearrangement $\mathrm{t}(8,9)(\mathrm{p} 22 ; \mathrm{p} 24)$ was found with increased transcription of different breakpoints in both genes, all these fusion proteins contain the helixloop-helix domain and completely tyrosine kinase 
domain of JAK2 $(36,37)$.

Two groups of French researchers have identified the same translocations in ACML and acute erythroid leukemia (38). Subsequently, this genetic disorder was seen in French patients with T- cell lymphoma (37). Such translocation leads to the activation of kinase structure of JAK2 due to helix-loop-helix domain of PCM1-induced oligomerization. T (8;9)induced fusion gene of PCM1-JAK1 is indicated in ACML with eosinophilia, AML, and T-cell lymphoma.

\section{BCR-JAK2 fusion}

CML is a kind of disease with positive Philadelphia chromosome, leading to expression of BCR-ABL fusion protein. Cytogenetic analysis in Germany on a patient with a typical CML resulted in the discovery of BCR-JAK2 rearrangement rather than BCRABL1. Translocation of $t(9 ; 22)(p 34 ; q 11)$ led to fusion of helix-loop-helix of BCR dimerization domain with catalytic JH1 domain in JAK2. As a result, this patient had no response to imatinib as specific inhibitor of ABL1 kinase. In fact, imatinib had no inhibitory activity against JAK2 (39).

After two years, a study in Italy reported $t(9 ; 22)$ (p24;q11) in patient with AML. Although, the occurrence of such translocation led to fusion of BCR and JAK2, however, breakpoints of BCR in this patient were different with those of the patient in Germany (40).

One year later, a study in Australia found $t(9 ; 22)$ (p24; q11.2), leading to BCR-JAK2 fusion in ACML patient with subcutaneous layer leukemia (41). Other translocations are also observed in JAK2 include SSBP2-JAK2 in pre-B ALL, PAX5-JAK2 and STRN3-JAK2 in children with ALL and SEC31JAK2 in classical non-Hodgkin lymphoma (42-44).

\section{RPN1-JAK2 fusion}

Ribophorin1 (RPN1)-JAK2 fusion were detected in PML resulting from mutually exclusive translocation $\mathrm{t}(3 ; 9)(\mathrm{q} 21 ; \mathrm{q} 24)(45)$.

\section{SSBP2-JAK2 fusion}

Rearrangement of regulatory gene transcription of SSBP2 with JAK2 was seen in a patient with preALL (42).

\section{PAX5-JAK2 fusion}

In the last decade, most recent fusion of JAK2 was discovered in a population of 466 children with ALL, which showed that binding domain to DNA of transcription factor PAX5 is fused to several kinase domains of JH1 in JAK2. In addition to JAK2 translocation, other gene rearrangements may also lead to increased expression and activity. For example, in a study on cell lineage of a case with Hodgkin-lymphoma telomere relocation increased the number of copies of several oncogenes such as JAK2 (21).

\section{Mutations found in the chronic phase MPN JAK2V617F}

JAK2V617F mutation as the most common in patients with MPN occurs in exson14 of HAK2 gene located in 9p24 chromosome. This mutation is seen in $96 \%$ of patients with PV and $65 \%$ of those with ET and PMF $(33,46,47)$. Such mutation affects the selfinhibitory action of the JH2 domain in JAK2 and leads to the activation of JAK2 structure and signal transduction of JAK/STAT.

Mice models with JAK2V617F mutation have a phenotype similar to PV with final development toward MF. Low expression of JAK2V617F leads to thrombocythemia and high level of JAK2V617F expression causes a PV phenotype in patients. However, clinical phenotype does not only depend on the expression level of JAK2V617F, and an increased polymorphism of STAT5 or STAT1 can induce megakaryopoiesis or erythropoiesis (48).

\section{Mutation of JAK exon 12}

Seventeen different mutations have been described in exon 12 of JAK2 that N542-E543 del, K539L, and E543D544 del are the most common them. Mutations in exon 12 lead to independent signaling of ligand in JAK2 that are recognized by overexpression of JAK2 phosphorylated and P-ERK1 and P-ERK2. In comparison to PVs with positive JAK2v617, mutations in exon 12 are resulted in significant increase in $\mathrm{Hb}$, and low level of platelets and leukocytes at the time of diagnosis. However, the incidence of thrombosis, myelofibrosis and leukemia are similar to ones with JAK2V617F mutation (49$51)$.

\section{MPL mutations}

MPL gene is located in chromosome 1 (p34), and can involve different mutations in exon10 of transmembrane domain of MPL receptor. The most common mutation is $\mathrm{W} 515 \mathrm{~L}$, leading to structural activation of JAK/STAT pathway. The frequency of mutations is ET and PMF $3-5 \%$ and $8-10 \%$, respectively. In mice models W515 mutation caused a phenotype- like PMF with thrombocytosis, splenomegaly and fibrosis. In some cases, MPL mutations and JAK2V617F are found together, indicating genetic complexity of MPN (52-54).

\section{TET2 mutation}

Ten eleven Translocation2 (TET2) is a tumor suppressor gene, located in chromosome 4 (q24), and 
frame shift, missense and non-sense mutations were found in that gene (55). Investigation of SCID NOD mice demonstrated that TEL2 may involve in selfrenewal pathways related to hematopoietic transformation. The incidence of TET2 mutations might observe before or past acquired mutation of JAK2, or happens as an independent event. TET2 mutations were demonstrated in a large number of individuals with MPN, including 16\% PV, 5\% ET, $17 \%$ PMF, $14 \%$ post-PV MF, $14 \%$ post-ET and $17 \%$ blast phase. However, such mutation has been observed in some other malignancies such as MDS, MPD/MDS syndrome and AML (56-58).

\section{LNK mutation}

LNK gene is located on chromosome 12 (q24.12), and codes a regulatory protein related to plasma membrane, conducting inhibition pathway of wildtype and mutated JAK2. Indeed, LNK is a negative regulatory for thrombopoietin-dependent JAK2 pathway. Interestingly, mice with LNK disorder have shown an increase in number of megakaryocyte and erythrocyte progenitors and self-renewal of HSC. Dysfunction mutations on LNK are in exon 12, describing low frequency in ET and PMF and erythropoiesis with low level of erythropoietin (59, 60).

\section{EZH2 Mutations}

Enhancer of zeste homolog 2 (EZH2) is located on chromosome 7 (q36.1), coding a subunit called polycomb repressive that is a strongly conserved methyl transferase, and affects stemce1/ renewal through epigenetic repression of genes involved in apoptosis. Mutations in the EZH2 have been found in myeloid leukemia, patients with MPN/MDS and MF $(61,62)$.

\section{Other mutations found in chronic phase NF1 Mutation}

Neurofibromatosis 1 gene is located on chromosome 7 (q11.2), and is associated with hereditary Von Reck Kinf housen neurofibromatosis. These patients have increased risk for various tumors such as myeloid leukemia. NF1 acts as inhibitory mediator of RAS signaling pathway. Cross-talking with STAT-JAK pathway and the role of NF1 can lead to a progressive MPN. NF1 mutations have been observed in a small percentage of patients with post-Et and post-PV MF; however, it was not reported in patients with chronic phase MPN (63).

\section{IDH1 and IDH2 Mutation}

Isocytrate dehydrogenase land 1-2 (IDH1-2) genes are located on chromosome 2 (q33.3) and chromosome 15 (q26.1), respectively. IDH1 mutation leads to production of 2-hydroxyglutarate. Its role is not fully understood in the initiation and growth of tumor, however, it appears to have a metaboliconcogenic role in the progression of MPN toward leukemia, and glioma pathogenesis. The incidence of this mutation in chronic phase MPN includes ET, PV and PMF less than 5\%, but in post MPN AML is about $21 \%(64,65)$.

\section{ASXL1 Mutation}

Additional Sex Combs-Linke1 (ASXL1) gene is located on chromosome 20 (q11.1) and it is belongs to the enhancer of trithorax and polycomb (ETP) genes that has role in activation and repress Hox (66). ASXL1 and TET2 mutations are caused increased self-renewal of MPN progenitors through regulating histones (67). ADXL1 mutations are observed in patient with MDS, AML, CMML, and JMML (68).

\section{CBL Mutations}

Casitas N-Lineage Lymphoma (C-CBL) gene is located on chromosome 11 (q23.3). CBL is a known protein, playing both negative and positive roles in tyrosine kinase pathway. Active CBL might act as an active tyrosine kinase to destroy some proteins and plays as an adaptor through recruiting several components related to downstream signaling transduction. Mutation in this gene has been identified in 17\% jMML and 6\% MPN (PMF) (69, 70).

\section{IKAROS Mutation}

Ikaros transcription factor is coded through IKZF1 gene located on chromosome 17 (p12), regulating hematopoiesis. In mice lacking the Ikaros function, lymphoproliferative disorders have been demonstrated in B and T-cell leukemia as well as anemia and thrombocytopenia. Phosphorus homozygous in IKZF1 gene in $21 \%$ post-MPN leukemia and $2.0 \%$ chronic phase MPN has been identified in MPN $(71,72)$.

\section{Role of TET2 in patients with Philadelphia- negative}

As mentioned, pre JAK2V617F is deletion of the long arm of chromosome 20. In some patients, MPN is MPN is considered delq20 that occurs before JAK2V617F mutation. However, opposite situations are seen in others. Hence, occurrence of del20q is independent and does not appear to be related to JAK2V617F mutation. Some researches in patients with MPN and JAK2V617F mutation showed remarkable evidence, that leukemia cells were negative in $50 \%$ of the patients. In 2009, mutation of TET2 and ASXL1 were identified in various myeloid neoplasms, including MPN (10\%). Like other 
members of the TET family, TET2, probably has a role in DNA methylation. Recently, it has been demonstrated that TET proteins lead to catalyze the conversion of methyl methionine to 5-hydroxymethyl methionine in DNA. TET2 mutations appear to cause changes in function of HSCs and proliferation of myeloid through epigenetic remodeling. Such mutations are substantial candidate for preJAK2V617F incidence. Indeed, studies in typical MPN patients indicate that most cells have both mutations; however, some cells have TET2 mutations without JAK2V617F mutations. Indeed, TET 2 mutation is an early incidence. Other MPN patients have clones with either JAK2V617F or TET2 mutations. In some cases, blast phase cells with TET2 disorders cannot be detected before mutation transformation $(27,73,74)$.

\section{Mutations associated with progression to AML}

Such mutations are mainly seen pre-AML myeloproliferative disorders but rarely found in chronic phase of the disease. Some gene mutations are associated with blast phase MPN, including IKZF, LNK, RUNX1, TP53, and IDH1/2.

Runt Related transcription factor (RUNX1)

Runx 1 protein is $\alpha$ subunit of transcription factor core binding factor (CBF). $\mathrm{CBF}$ is critical for hematopoiesis. Translocation and point mutations are mainly seen in AML, and MDS. RUNX1 mutations are rare in MPN chronic phase, but they have been detected in $27 \%$ of patients with blast phase (18 out of 50). In another study, $37.5 \%$ of patients (6 out of 16) with post-MPN AML were positive for Runx1. Mutations often occur in Runt domain and are heterozygote, and probably associated with lack of function (75-77).

TP53

TP53 encodes a tumor suppressor gene, playing a central role in the cellular response to stress. Moreover, this gene can repair DNA, induces cell cycle arrest, apoptosis, and post- genetic damage quiescence. TP53 is one of the most common mutations in cancers. TP53 mutations are rare in chronic phase of MPN, however, are found in 20\% patients (4 out of 16) with post-MPN AML. Mutations are resulted in loss of Protein function, and in all cases, 2 alleles were affected. In another study, TP53 mutations were found in $27.3 \%$ and $31 \%$ of post-MPN AML and chronic phase of disease (heterozygote mutations), respectively. In both studies, TP53 mutation has been indicated in chronic phase of pre-AML suggesting it may be useful to assess progress toward AML. Furthermore, chromosome replication has been demonstrated in $0.32 \%$ and $18.8 \%$ chronic phase of disease and post MPN AML MDM4. Region replicated, carrying MDM4, is a TP53 inhibitor in another malignancy. In this study, TP53 mutations and 1q duplicated are exclusive, suggesting a similar role for two genetic changes. In total, $45.5 \%$ patients with post-MPN AML have an abnormality in TP53 or chromosome lq $(78-80)$.

\section{IKAROS family zinc finger 1 (IKZF1)}

This gene encodes IKZF1, a transcription factor related to chromatin modification, is essential for normal hematopoiesis. IKZF1 mutations in lymphoid malignancies have been described as specific deletion in chromosome-positive ALL. IKZF deletions are seen in less than $1 \%$ chronic phase and $20 \%$ postMPN AML. Deficient of main IKZF1 deletions in chronic phase of seven patients with AML suggest that IKZF1 mutations may be a late event in the progression to AML, and therefore, not useful as a surrogate marker $(81,82)$.

A summary of the different MPN mutations is shown in Table 1.

Table 1. Mutation which is found in the different stages of MPN

\begin{tabular}{llll}
\hline JAK2 mutation (35-40) & $\begin{array}{l}\text { Mutations found in the } \\
\text { chronic phase MPN (42-50) }\end{array}$ & $\begin{array}{l}\text { Other mutations found in } \\
\text { chronic phase (61-66) }\end{array}$ & $\begin{array}{l}\text { Mutations associated with progression to } \\
\text { AML (72-78) }\end{array}$ \\
\hline ETV6/TEL-JAK2 Fusion & JAK2V617F & NF1 Mutation & Runt Related transcription factor (RUNX1) \\
BCR-JAK2 fusion & JAK exon12 mutation & IDH1 and IDH2 Mutation & TP53 \\
PCM1-JAK2 fusion & MPL mutations & ASXL1 Mutation & IKAROS family zinc finger1 (IKZF1) \\
RPN1-JAK2 fusion & TET2 mutation & CBL Mutations & \\
SSBP2-JAK2 fusion & LNK mutation & IKAROS Mutation & \\
PAX5-JAK2 fusion & EZH2 Mutations & & \\
\hline
\end{tabular}




\section{Conflict of Interest}

The authors declare that they have no conflict of interest in this work.

\section{References}

1. Santos FP, Verstovsek S. JAK2 inhibitors: What's the true therapeutic potential? Blood Rev. 2011; 25(2):53-63. PMID: 21095048 .

2. Mesa RA, Silverstein MN, Jacobsen SJ, Wollan PC, Tefferi A. Population-based incidence and survival figures in essential thrombocythemia and agnogenic myeloid metaplasia: An Olmsted county study, 1976-1995. Am J Hematol. 1999; 61(1):10-5. PMID: 10331505 .

3. Mithraprabhu S, Grigoriadis G, Khong T, Spencer A. Deactylase inhibition in myeloproliferative neoplasms. Invest New Drugs. 2010; 28 Suppl 1:S50-7. PMID: 21127942

4. Jemal A, Siegel R, Ward E, Murray T, Xu J, Thun MJ. Cancer statistics, 2007. CA Cancer J Clin. 2007; 57(1):43-66. PMID: 17237035

5. Mascarenhas J, Mughal T, Verstovsek S. Biology and clinical management of myeloproliferative neoplasms and development of the JAK inhibitor ruxolitinib. Curr Med Chem. 2012; 19(26):4399413. PMID: 22830345

6. Tefferi A, Vardiman J. Classification and diagnosis of myeloproliferative neoplasms: the 2008 World Health Organization criteria and point-of-care diagnostic algorithms. Leukemia. 2007; 22(1):14-22. PMID: 17882280

7. Tefferi A, Thiele J, Vardiman JW. The 2008 World Health Organization classification system for myeloproliferative neoplasms. Cancer. 2009; 115(17):3842-7. PMID: 19472396

8. Verstovsek S, Manshouri T, Quintás-Cardama A, Harris D, Cortes J, Giles FJ, et al. WP1066, a novel JAK2 inhibitor, suppresses proliferation and induces apoptosis in erythroid human cells carrying the JAK2 V617F mutation. Clin Cancer Res. 2008; 14(3):788-96. PMID: 18245540

9. Firmbach-Kraft I, Byers M, Shows T, Dalla-Favera R, Krolewski J. tyk2, prototype of a novel class of non-receptor tyrosine kinase genes. Oncogene. 1990; 5(9):1329-36. PMID: 2216457

10. Vainchenker W, Dusa A, Constantinescu SN, editors. JAKs in pathology: role of Janus kinases in hematopoietic malignancies and immunodeficiencies. Seminars Cell Dev Biol. 2008; 19(4):385-93. PMID: 18682296

11. Kiss R, Polgár T, Kirabo A, Sayyah J, Figueroa NC, List AF, et al. Identification of a novel inhibitor of JAK2 tyrosine kinase by structure-based virtual screening. Bioorg Med Chem Lett. 2009; 19(13):3598-601. PMID: 19447617

12. Luo H, Hanratty W, Dearolf C. An amino acid substitution in the Drosophila hopTum-l Jak kinase causes leukemia-like hematopoietic defects. EMBO J. 1995; 14(7):1412-20. PMID: 7729418

13. Sayyah J, Sayeski PP. Jak2 inhibitors: rationale and role as therapeutic agents in hematologic malignancies. Curr Oncol Rep. 2009; 11(2):117-24. PMID: 19216843

14. Saharinen P, Vihinen M, Silvennoinen O. Autoinhibition of Jak2 tyrosine kinase is dependent on specific regions in its pseudokinase domain. Mol Biol Cell. 2003; 14(4):1448-59. PMID: 12686600

15. Baffert F, Régnier CH, De Pover A, Pissot-Soldermann C, Tavares GA, Blasco F, et al. Potent and selective inhibition of polycythemia by the quinoxaline JAK2 inhibitor NVP-BSK805. Mol Cancer Ther. 2010; 9(7):1945-55. PMID: 20587663

16. Darnell JE. STATs and gene regulation. Science. 1997; 277(5332):1630-5. PMID: 9287210

17. Schaefer TS, Sanders LK, Nathans D. Cooperative transcriptional activity of Jun and Stat 3 beta, a short form of Stat3. Proc Natl Acad Sci U S A. 1995; 92(20):9097-101. PMID: 7568080

18. Cacalano NA, Migone TS, Bazan F, Hanson EP, Chen M, Candotti F, et al. Autosomal SCID caused by a point mutation in the N-terminus of Jak3: mapping of the Jak3-receptor interaction domain. EMBO J. 1999; 18(6):1549-58. PMID: 1007592

19. Leonard WJ, O'Shea JJ. Jaks and STATs: biological implications*. Annu Rev Immunol. 1998; 16(1):293-322. PMID: 9597132

20. O'Shea JJ. Jaks, STATs, cytokine signal transduction, and immunoregulation: are we there yet? Immunity. 1997; 7(1):1-11. PMID: 9252115

21. Jatiani SS, Baker SJ, Silverman LR, Reddy EP. JAK/STAT pathways in cytokine signaling and myeloproliferative disorders approaches for targeted therapies. Genes Cancer. 2010; 1(10):97993. PMID: 21442038

22. Walter MJ, Ding L, Shen D, Shao J, Grillot M, McLellan M, et al. Recurrent DNMT3A mutations in patients with myelodysplastic syndromes. Leukemia. 2011; 25(7):1153-8. PMID: 21415852

23. Kirabo A, Park SO, Majumder A, Gali M, Reinhard MK, Wamsley HL, et al. The Jak2 Inhibitor, G6, Alleviates Jak2V617F- Mediated Myeloproliferative Neoplasia by Providing Significant Therapeutic Efficacy to the Bone Marrow. Neoplasia. 2011; 13(11):1058-68. PMID: 22131881

24. Levine RL, Wadleigh M, Cools J, Ebert BL, Wernig G, Huntly $\mathrm{BJ}$, et al. Activating mutation in the tyrosine kinase JAK2 in polycythemia vera, essential thrombocythemia, and myeloid metaplasia with myelofibrosis. Cancer Cell. 2005; 7(4):387-97. PMID: 15837627

25. Shannon K, Van Etten RA. JAKing up hematopoietic proliferation. Cancer Cell. 2005; 7(4):291-3. PMID: 15837617

26. Delhommeau F, Jeziorowska D, Marzac C, Casadevall N. Molecular aspects of myeloproliferative neoplasms. Int J Hematol. 2010; 91(2):165-73. PMID: 20186505

27. Tefferi A. Novel mutations and their functional and clinical relevance in myeloproliferative neoplasms: JAK2, MPL, TET2, ASXL1, CBL, IDH and IKZF1. Leukemia. 2010; 24(6):1128-38. PMID: 20428194.

28. Passamonti F, Maffioli M, Caramazza D, Cazzola M. Myeloproliferative neoplasms: From JAK2 mutations discovery to JAK2 inhibitor therapies. Oncotarget. 2011; 2(6):485. PMID: 21646683

29. Levine RL, Pardanani A, Tefferi A, Gilliland DG. Role of JAK2 in the pathogenesis and therapy of myeloproliferative disorders. Nat Rev Cancer. 2007; 7(9):673-83. PMID: 1772143 
30. Malinge S, Ben-Abdelali R, Settegrana C, Radford-Weiss I, Debre M, Beldjord K, et al. Novel activating JAK2 mutation in a patient with Down syndrome and B-cell precursor acute lymphoblastic leukemia. Blood. 2007; 109(5):2202-4. PMID: 17068151

31. Toyama K, Karasawa M, Yokohama A, Mitsui T, Uchiumi H, Saitoh T, et al. Differences in the JAK2 and MPL mutation status in the cell lineages of the bcr/abl-negative chronic myeloproliferative neoplasm subtypes. Intern Med. 2011; 50(21):2557-61. PMID: 22041356

32. Baxter EJ, Scott LM, Campbell PJ, East C, Fourouclas N, Swanton S, et al. Acquired mutation of the tyrosine kinase JAK2 in human myeloproliferative disorders. Lancet. 2005; 365(9464):1054-61. PMID: 15781101

33. Kralovics R, Passamonti F, Buser AS, Teo S-S, Tiedt R, Passweg JR, et al. A gain-of-function mutation of JAK2 in myeloproliferative disorders. N Engl J Med. 2005; 352(17):177990. PMID: 15858187

34. Lacronique V, Boureux A, Della Valle V, Poirel H, Quang CT, Mauchauffé M, et al. A TEL-JAK2 fusion protein with constitutive kinase activity in human leukemia. Science. 1997; 278(5341):1309-12. PMID: 9360930

35. Cuesta-Domínguez Á, Ortega M, Ormazábal C, SantosRoncero M, Galán-Díez M, Steegmann JL, et al. Transforming and tumorigenic activity of JAK2 by fusion to BCR: molecular mechanisms of action of a novel BCR-JAK2 tyrosine-kinase. PLoS One. 2012; 7(2):e32451. PMID: 22384256

36. Reiter A, Walz C, Watmore A, Schoch C, Blau I, Schlegelberger B, et al. The $t(8 ; 9)(p 22 ; p 24)$ is a recurrent abnormality in chronic and acute leukemia that fuses PCM1 to JAK2. Cancer Res. 2005; 65(7):2662-7. PMID: 15805263

37. Adelaide J, Perot C, Gelsi-Boyer V ,Pautas C, Murati A, Copie-Bergman C, et al. A t $(8 ; 9)$ translocation with PCM1-JAK2 fusion in a patient with T-cell lymphoma. Leukemia. 2006; 20(3):536-7. PMID: 16424865

38. Bousquet M, Quelen C, De Mas V, Duchayne E, Roquefeuil B, Delsol G, et al. The t $(8 ; 9)$ (p22; p24 (translocation in atypical chronic myeloid leukaemia yields a new PCM1-JAK2 fusion gene. Oncogene. 2005; 24(48):7248-52. PMID: 16091753

39. Skoda R. The genetic basis of myeloproliferative disorders. Hematology Am Soc Hematol Educ Program. 2007: 1-10. PMID: 18024602

40. Jekarl DW, Han SB, Kim M, Lim J, Oh E-J, Kim Y, et al. JAK2 V617F mutation in myelodysplastic syndrome, myelodysplastic syndrome/myeloproliferative neoplasm, unclassifiable, refractory anemia with ring sideroblasts with thrombocytosis, and acute myeloid leukemia. Korean J Hematol. 2010; 45(1):46-50. PMID: 21120162

41. Lane SW, Fairbairn DJ, McCarthy C, Nandini A, Perry-Keene J, Kennedy GA. Leukaemia cutis in atypical chronic myeloid leukaemia with at $(9 ; 22)(\mathrm{p} 24 ; \mathrm{q} 11.2)$ leading to BCR-JAK2 fusion. Br J Haematol. 2008; 142(4):503. PMID: 18537978

42. Poitras JL, Cin PD, Aster JC, DeAngelo DJ, Morton CC. Novel SSBP2-JAK2 fusion gene resulting from at $(5 ; 9)(\mathrm{q} 14.1 ; \mathrm{p} 24.1)$ in pre-B acute lymphocytic leukemia. Genes Chromosomes Cancer. 2008; 47(10):884-9. PMID: 18618714

43. Nebral K, Denk D, Attarbaschi A, König M, Mann G, Haas
$\mathrm{OA}$, et al. Incidence and diversity of PAX5 fusion genes in childhood acute lymphoblastic leukemia. Leukemia. 2008; 23(1):134-43. PMID: 19020546

44. Van Roosbroeck K, Cox L, Tousseyn T, Lahortiga I, Gielen O, Cauwelier B, et al .JAK2 rearrangements, including the novel SEC31A-JAK2 fusion, are recurrent in classical Hodgkin lymphoma. Blood. 2011; 117(15):4056-64. PMID: 21325169

45. Olcaydu D, Kralovics R. The role of janus kinases in hematopoietic malignancies: Springer; 2012. 239-58.

46. Kralovics R, Passamonti F, Buser AS, Teo S-S, Tiedt R, Passweg JR, et al. A gain-of-function mutation of JAK2 in myeloproliferative disorders. N Engl J Med. 2005; 352(17):177990. PMID: 15858187

47. Shi L, Wang S, Zangari M, Xu H, Cao TM, Xu C, et al. Overexpression of CKS1B activates both MEK/ERK and JAK/STAT3 signaling pathways and promotes myeloma cell drug-resistance. Oncotarget. 2010; 1(1):22-23. PMID: 20930946

48. Chen E, Beer PA, Godfrey AL, Ortmann CA, Li J, CostaPereira AP, et al. Distinct clinical phenotypes associated with JAK2V617F reflect differential STAT1 signaling. Cancer Cell. 2010; 18(5):524-35. PMID: 21074499

49. Scott LM, Tong W, Levine RL, Scott MA, Beer PA, Stratton $\mathrm{MR}$, et al. JAK2 exon 12 mutations in polycythemia vera and idiopathic erythrocytosis. N Engl J Med. 2007; 356(5):459-68. PMID: 17267906

50. Martínez-Avilés L, Besses C, Álvarez-Larrán A, Cervantes F, Hernández-Boluda JC, Bellosillo B. JAK2 exon 12 mutations in polycythemia vera or idiopathic erythrocytosis. Haematologica. 2007; 92(12):1717-8. PMID: 18056003

51. Pardanani A, Lasho $\mathrm{T}$, Finke $\mathrm{C}$, Hanson C, Tefferi A. Prevalence and clinicopathologic correlates of JAK2 exon 12 mutations in JAK2V617F-negative polycythemia vera. Leukemia. 2007; 21(9):1960-3. PMID: 17597810

52. Pikman Y, Lee BH, Mercher T, McDowell E, Ebert BL, Gozo $\mathrm{M}$, et al. MPLW515L is a novel somatic activating mutation in myelofibrosis with myeloid metaplasia .PLoS Med. 2006; 3(7):e270. PMID: 16834459

53. Pikman Y, Lee BH, Mercher T, McDowell E, Ebert BL, Gozo $\mathrm{M}$, et al. MPLW515L is a novel somatic activating mutation in myelofibrosis with myeloid metaplasia. PLoS Med. 2006; 3(7):e270. PMID: 16834459

54. Pardanani AD, Levine RL, Lasho T, Pikman Y, Mesa RA, Wadleigh M, et al. MPL515 mutations in myeloproliferative and other myeloid disorders: a study of 1182 patients. Blood. 2006; 108(10):3472-6. PMID: 16868251

55. Tefferi A, Pardanani A, Lim K, Abdel-Wahab O, Lasho T, Patel $\mathrm{J}$, et al. TET2 mutations and their clinical correlates in polycythemia vera ,essential thrombocythemia and myelofibrosis. Leukemia. 2009; 23(5):905-11. PMID: 19262601

56. Tefferi A, Lim K, Abdel-Wahab O, Lasho T, Patel J, Patnaik $\mathrm{M}$, et al. Detection of mutant TET2 in myeloid malignancies other than myeloproliferative neoplasms: CMML, MDS, MDS/MPN and AML. Leukemia. 2009; 23(7):1343-5. PMID: 19295549

57. Schaub FX, Looser R, Li S, Hao-Shen H, Lehmann T, Tichelli A, et al. Clonal analysis of TET2 and JAK2 mutations suggests that TET2 can be a late event in the progression of 
myeloproliferative neoplasms. Blood. 2010; 207(10); 115; 10. PMID: 20061559

58. Jankowska AM, Szpurka H, Tiu RV, Makishima H, Afable M, Huh J, et al. Loss of heterozygosity $4 \mathrm{q} 24$ and TET2 mutations associated with myelodysplastic/myeloproliferative neoplasms. Blood. 2009; 113(25):6403-10. PMID: 19372255

59. Tong W, Zhang J, Lodish HF. Lnk inhibits erythropoiesis and Epo-dependent JAK2 activation and downstream signaling pathways. Blood. 2005; 105(12):4604-12. PMID: 15705783

60. Oh ST, Simonds EF, Jones C, Hale MB, Goltsev Y, Gibbs KD, et al. Novel mutations in the inhibitory adaptor protein LNK drive JAK-STAT signaling in patients with myeloproliferative neoplasms. Blood. 2010; 116(6):988-92. PMID: 20404132

61. Simon C, Chagraoui J, Krosl J, Gendron P, Wilhelm B, Lemieux $\mathrm{S}$, et al. A key role for EZH2 and associated genes in mouse and human adult T-cell acute leukemia. Genes Dev. 2012; 26(7):651-6. PMID: 22431509

62. Tanaka S, Miyagi S, Sashida G, Chiba T, Yuan J, MochizukiKashio M, et al. Ezh2 augments leukemogenicity by reinforcing differentiation blockage in acute myeloid leukemia. Blood. 2012; 120(5):1107-17. PMID: 22677129

63. Reynolds R, Browning G, Nawroz I, Campbell I. Von Recklinghausen's neurofibromatosis: neurofibromatosis tye1. Lancet. 2003; 361(9368):1552-4. PMID: 12737880

64. Green A, Beer P. Somatic mutations of IDH1 and IDH2 in the leukemic transformation of myeloproliferative neoplasms. New $\mathrm{N}$ Engl J Med. 2010; 362(4):369-70. PMID: 20107228

65. Pardanani A, Lasho T, Finke C, Mai M, McClure R, Tefferi A. IDH1 and IDH2 mutation analysis in chronic-and blast-phase myeloproliferative neoplasms. Leukemia. 2010; 24(6):1146-51. PMID: 20410924

66. Fisher CL, Pineault N, Brookes C, et al: Loss of- function additional sex combs like 1 mutations disrupt hematopoiesis but do not cause severe myelodysplasia or leukemia. Blood. 2010; 115(1):38-46. PMID: 19861679

67. Passamonti F, Maffioli M, Caramazza D, Cazzola M. Myeloproliferative neoplasms: From JAK2 mutations discovery to JAK2 inhibitor therapies. Oncotarget. 2011; 2(6):485-90. PMID: 21646683

68. Boultwood J, Perry J, Pellagatti A, et al: Frequent mutation of the polycomb-associated gene ASXL1 in the myelodysplastic syndromes and in acute myeloid leukemia. Leukemia. 2010; 24(5):1062-5. PMID: 20182461

69. Grand FH, Hidalgo-Curtis CE, Ernst T, Zoi K, Zoi C, McGuire $\mathrm{C}$, et al. Frequent CBL mutations associated with $11 \mathrm{q}$ acquired uniparental disomy in myeloproliferative neoplasms. Blood. 2009; 113(24): 6128-92. PMID: 19387008

70. Loh ML, Sakai DS, Flotho C, Kang M, Fliegauf M, Archambeault $\mathrm{S}$, et al. Mutations in CBL occur frequently in juvenile myelomonocytic leukemia. Blood. 2009;114(9):1859-63. PMID: 19571318
71. Jäger R, Gisslinger H, Passamonti F, Rumi E, Berg T, Gisslinger B, et al. Deletions of the transcription factor Ikaros in myeloproliferative neoplasms. Leukemia. 2010; 24(7):1290-8. PMID: 20508609

72. Jäger R1, Gisslinger H, Passamonti $F$, Rumi E, Berg T, Gisslinger B. Deletions of the transcription factor Ikaros in myeloproliferative neoplasms. Lukemia. 2010; 24(7): 1290-8. PMID: 20508609

73. Patriarca A, Colaizzo D, Tiscia G, Spadano R, Di Zacomo S, Spadano A, et al. TET2 Mutations in Ph-Negative Myeloproliferative Neoplasms: Identification of Three Novel Mutations and Relationship with Clinical and Laboratory Findings. Biomed Res Int. 2013; 2013:929840. PMID: 23781511

74. Olcaydu D, Rumi E, Harutyunyan A, Passamonti F, Pietra D, Pascutto C, et al. The role of the JAK2 GGCC haplotype and the TET2 gene in familial myeloproliferative neoplasms. Haematologica. 2011; 96(3):367-74. PMID: 21173100

75. Lo Coco F, Pisegna S, Diverio D. The AML1 gene: a transcription factor involved in the pathogenesis of myeloid and lymphoid leukemias. Haematologica. 1997; 82(3):364-70. PMID: 9234595

76. Cammenga J, Niebuhr B, Horn S, Bergholz U, Putz G, Buchholz F, et al. RUNX1 DNA-binding mutants, associated with minimally differentiated acute myelogenous leukemia, disrupt myeloid differentiation. Cancer Res. 2007; 67(2):537-45. PMID: 17234761

77. Osato M, Asou N, Abdalla E, Hoshino K, Yamasaki H, Okubo $\mathrm{T}$, et al. Biallelic and Heterozygous Point Mutations in the Runt Domain of theAML1/PEBP2alpha B Gene Associated With Myeloblastic Leukemias. Blood. 1999; 93(6):1817-24. PMID: 10068652

78. Szymanska K, Hainaut P. TP53 and mutations in human cancer. Acta Biochimica Polonica-english edition. 2003; $50(1): 231-8$

79. Harutyunyan A, Klampfl T, Cazzola M, Kralovics R. p53 lesions in leukemic transformation. $\mathrm{N}$ Engl J Med. 2011; 364(5):488-90. PMID: 21288114

80. Oren M, Rotter V. Mutant p53 gain-of-function in cancer. Cold Spring Harbor perspectives in biology. 2010; 2(2): a001107.

81. Chen I-M, Harvey RC, Mullighan CG, Gastier-Foster J, Wharton W, Kang H, et al. Outcome modeling with CRLF2, IKZF1, JAK, and minimal residual disease in pediatric acute lymphoblastic leukemia: a Children's Oncology Group study. Blood. 2012; 119 (15): 3512-22. PMID: 22368272

82. Mullighan CG, Su X, Zhang J, Radtke I, Phillips LA, Miller $\mathrm{CB}$, et al. Deletion of IKZF1 and prognosis in acute lymphoblastic leukemia. N Engl J Med. 2009; 360(5):470-80. PMID: 19129520 